\title{
Editorial
}

\section{Public diplomacy and place branding: Where's the link?}

Place Branding (2006) 2, 271-275. doi:10.1057/palgrave.pb.6000040

Last March, a conference on Public Diplomacy was held at Wilton Park, the conference centre of the United

Kingdom's Foreign and Commonwealth Office. Public diplomacy (PD)

practitioners and academics from several different countries attended the event, and a lively discussion emerged around the future of PD. One strand of the debate that particularly interested me centred on the connection between PD and the new, less well understood, but more and more frequently mentioned discipline of nation branding.

Delegates sought to understand whether these were simply two versions of the same idea, one seen from an international relations perspective and the other from a more commercial angle, or whether they were in fact entirely different concepts; and if different, to what extent were they linked or compatible.

The view I expressed to the conference was that PD is in fact a subset of Nation Branding: I have always intended Nation Branding to consider how the nation as a whole presents and represents itself to other nations, whereas PD appears to concentrate exclusively on the presentation and representation of government policy to other publics: in other words, the international equivalent of what is usually known as Public Affairs, or a type of diplomacy where the interlocutor is society at large rather than other diplomats or ministers.
According to my theory of nation branding as previously described in these pages, government policy is simply one point of the 'hexagon' of nation brand, one-sixth of the picture which nations habitually paint of themselves, whether by accident or by design. From this point of view, PD is clearly a component of nation branding: it is concerned with presenting one aspect of national activity, while nation branding attempts to harmonise policy, people, sport and culture, products, tourism, trade and investment promotion and talent recruitment.

Since the Wilton Park conference, my views on this matter have changed. My contention then that PD is a subset of nation branding was, I realise, based on a rather conventional interpretation of PD as a means of presentation and representation of the national interest: in other words, that it was primarily concerned with the communication of policies rather than with their execution or conception. This seems to be doing the discipline a disservice, even if there are as yet few examples of PD rising above its conventional role of press and public affairs agency to the Ministry of Foreign Affairs: potentially, PD is the 'master discipline' of international relations for developed and prominent countries just as Nation Branding is potentially the " master discipline' of economic development for emerging and less wellknown countries. 
Ironically, my initially rather narrow view of PD was precisely analogous to the interpretation of nation branding against which I have been battling for the last ten years: the idea that brand management for a nation (or city, or region) is simply a matter of marketing or promoting the place. During this period I have advanced many arguments for why this is often neither wise, effective nor even possible, and that the huge expenditures by governments on national promotional campaigns are, more often than not, a waste of taxpayers' or donors' money. National image, I have argued, is like a juggernaut without wheels, and imagining that it can really be shifted by so weak an instrument as marketing communications is an extravagant delusion. People don't change their views about countries - views they may have held for decades - simply because a marketing campaign tells them to. Most publics today, I have always maintained, are simply too well inoculated against advertising and too savvy about the media to believe mere government propaganda.

Similar arguments have often been levied against conventional PD by its wiser practitioners. When Edward R Murrow, the 'father' of American PD and head of the United States Information Agency (USIA) found out about the CIA's botched attempt to invade Cuba at the Bay of Pigs in April 1961, he was 'spitting mad', as the then Voice of America director, Henry Loomis, recalls. 'They expect us to be in on the crash landings', Murrow said to Loomis, 'We had better be in on the takeoffs [too]'.

President Kennedy apparently took this advice, for in January 1963 his administration issued the USIA new orders. Its role would no longer be merely to inform and explain US objectives; it would be 'to help achieve United States foreign policy objectives by... influencing public attitudes in other nations'. This explicitly shifted the mission from information provision to persuasion, and from commentator (or apologist) to actor. The USIA would also have responsibility for 'advising the President, his representatives abroad, and the various departments and agencies on the implications of foreign opinion for present and contemplated United States policies, programmes and official statements.'

The debate continues to this day, and Karen Hughes, the current Under-Secretary for PD at the US State Department, has frequently stressed that her job should not be limited to the communication of government policy: 'being in at the takeoffs' means having an influence over the formation of those policies too. Her close relationship with President George W Bush has been taken as an encouraging sign by the PD community that her department now stands a real chance of achieving its aims, since it is in a better position to have some influence over the way the 'takeoffs' are planned.

The main challenge to Ms Hughes's work, however, may not, after all, have much to do with her closeness to the President or the influence she wields over US foreign policy: in the end, it is more likely to be the image, credibility and reputation of the country whose policies she seeks to justify.

If the purpose of PD is simply to promote government policies, it is likely to be superfluous or futile, depending on the good name of the country and its government at that particular time. If the country is generally in favour, then unless the policy is patently wrongheaded, it is likely to be well received by publics and simply needs to be clearly communicated. Little art or skill is required to do this. If on the other hand the country suffers from a poor or weak reputation, especially in the area relating to the policy, then almost no amount of promotional skill or expenditure can cause that policy to be received with enthusiasm, and it will either be ignored or taken as further proof of whatever evil is currently ascribed to the country. This is why I have often defined brand image as the context in which messages are received, not the messages themselves.

Clearly, the reputation of a country's current government may be held in higher or lower esteem than the underlying 'brand image' of the 
nation as a whole, and this is an additional complicating factor for governments attempting to understand how best to manage their international dialogue. When the nation has a better 'brand' than its government (a situation which is much more common than the converse), unpopular government policies may do little harm to the country's overall longer-term interests, but it is likely that an internationally unpopular government may over a long period cause damage to the 'nation brand' which is very difficult to undo, as I have argued in a recent book. ${ }^{1}$

The complexity of understanding and managing public, rather than professional opinion, points to one of the key differences between traditional diplomacy and PD. When the target is a restricted and professional audience such as diplomats and ministers, the background reputation of the country in question, while it undoubtedly does play a role in conditioning those individuals' responses to its policies, has only a limited and indirect impact on the way in which they evaluate them. Such professional audiences are more likely to consider policies on their own merits, in detail, and to some degree in isolation of previous policies from the same country or even government. It is, in fact, one of the fundamental principles of diplomacy that the fairest, most informed and most balanced view possible are always taken of any government's actions and their presumed motivations. Diplomats are, or should be, fully prepared to change their minds about any country at any point.

Publics, on the other hand, have neither the expertise, the experience, the habit nor the desire to consider the actions of foreign governments so carefully and in so even-handed a manner, and their responses to those governments' policies are likely to be directly and substantially conditioned by their perceptions of the country as a whole. As I have often commented, it is a common tendency of publics to hold on very tightly to a rather simplistic view of countries once it is formed (especially when considering more distant countries or those with which they have no particular connection), and the data from the Anholt Nation Brands Index confirms that underlying public perceptions of countries are remarkably stable. The views of publics are therefore easier to measure and understand, but much harder to alter, whereas the views of governments and their foreign services may be harder to measure and understand, but at least in theory are more susceptible to alteration.

The comparison is analogous to the different ways in which a judge and a jury consider the prisoner in the dock: the trained legal mind will concentrate primarily on the supposed offence and on the evidence, whereas the public will tend to concentrate on the accused, the victim, and on their presumed characters, and may easily be led astray by circumstantial evidence. For this reason, considerable thought is given in most democratic countries to artificial ways of preventing the jury from taking previous offences into consideration when reaching their verdict. In the court of international public opinion, of course, there can be no such provisions, and governments are thus largely at the mercy of their international reputation, and to a great extent the passive beneficiaries or victims of generations of their predecessors' wisdom or foolishness.

Wise people have always understood that people's perceptions of the messenger can be more important than the message itself. The English novelist Anthony Trollope makes exactly the same point in his 1881 novel, Dr Wortle's School:

So much in this world depends on character that attention has to be paid to bad character even when it is not deserved. In dealing with men and women, we have to consider what they believe, as well as what we believe ourselves. The utility of a sermon depends much on the idea that the audience has of the piety of the man who preaches it. Though the words of God should never have come with greater power from the mouth of man, they will come in vain if they be uttered by one who is known as a breaker of the Commandments; - they will come in vain from the mouth of one who is even suspected to be so. 
For this reason, $\mathrm{PD}$ is an emasculated discipline unless it has some power to affect the background reputation of the country whose policies it attempts to represent; and since that background reputation can only be significantly altered by policies, not by communications, the critical success factor for PD is whether its connection to policy making is one way or two way. If there is a two-way mechanism that allows the PD function to pass back recommendations for policy making, and these recommendations are taken seriously and properly valued by government as critical 'market feedback', then PD has a chance of enhancing the good name of the country, thus ensuring that future policy decisions are received in a more favourable light. It's a virtuous circle, because of course under these circumstances the policies need far less 'selling'.

Simply ensuring that the PD function has an influence over government policies, however, can only have a limited impact on the background reputation of countries. According to my theory of nation branding, it is only when PD is carried out in coordination with the full complement of national stakeholders as well as the main policy makers, and all are linked through effective brand management to a single, long-term national strategy, that the country has a real chance of affecting its image and making it into a competitive asset rather than an impediment or a liability. National governments are simply not in control of all of the forces that shape their country's image, and neither is any other single body within the nation. The Tourist Board cannot control government policies, yet those policies can dramatically affect its business; the success of the Investment Promotion Agency may be influenced by the communications of the Tourist Board or the Cultural Institute; institutes of higher education might find that their attempts to attract talent from overseas are affected by the reputation of the products and services exported from the country or the behaviour of prominent athletes or media stars from the same country, and so on. National image is communicated through a complex web of channels and sectors, and none of the 'owners' of those channels have absolute control over all the factors that affect their interests.

In synthesis, I think it is helpful to consider PD as having three distinct stages of evolution or sophistication. Stage I PD is 'pre-Murrow' PD, where PD officers are simply charged to 'sell' whatever policies the administration chooses to implement. A comment from a US government official to a PD officer that appeared in John Brown's Public Diplomacy Press Review this week perfectly characterises Stage I PD:

'Look, you just forget about policy, that's not your business; we'll make the policy and then you can put it on your damn radios. ${ }^{2}$

Stage II PD is the 'post-Murrow' stage, where the function is still basically to 'sell' government policies, but PD officers are 'in at the take-offs', and thus have some power to condition the style and indeed the content of foreign policy.

There is a parallel here in the commercial sector when branding becomes fully represented in the boardroom: here, the marketing function is recognised as the corporation's 'eyes and ears on the ground' and its link with the marketplace, not merely informing strategy but actually driving innovation and new product development.

Stage III PD uses the tools of PD in a different way altogether, and has seldom been consistently or well used by governments: this is $\mathrm{PD}$ as an instrument of policy, rather than as a method of communication. Here, a wide range of non-military methods (which include but are not necessarily limited to communications techniques) are used in order to bring about changes in the behaviours of populations, either in order to cause them to bring about policy changes through democratic influence over their own governments, or even by direct action.

The appeal of such an instrument of 'soft power' hardly needs emphasising. For a country desiring regime change in another country, for example, the prospect of being able to persuade the other country's population to replace their own government is incomparably preferable 
(not to mention far cheaper) than doing it by direct military intervention. Not surprisingly, there have been numerous attempts in the past to achieve such ends, ranging from deliberate rumour-mongering to fake broadcasting; and some real successes have been achieved through the use of cultural diplomacy, although of course the effectiveness of such methods is notoriously hard to measure as cultural influence is always a slow-burning and indirect influence. Few now dispute that the deliberate dissemination of American popular culture into the Soviet Union played a part in helping to defeat Communism, and many would argue that when the struggle is genuinely an ideological one - as was the case during the Cold War then cultural diplomacy may well be a more appropriate weapon than warfare. Given that the biggest threats to world peace today are primarily ideological in nature, it seems surprising that the lessons of the Cold War appear not to have been well learned. Where culture is the problem, culture is also likely to be the solution.

In the modern age, it also seems natural that governments should turn to the world of commerce for guidance in this area, since creating wide-scale changes in opinion and behaviour through persuasion rather than coercion, through attraction rather than compulsion, is seen to be the essence of branding and marketing. To 'brand' democracy, for example, and thus create widespread 'purchase' of the democratic 'product' in undemocratic countries, would surely be the least harmful, most cost-effective and most benign instrument of foreign policy that human ingenuity could devise. It would indeed be a mark of human progress if nations could discover ways of persuading each other to change their behaviour - and only when this is necessary for the greater good, of course: the peak of human civilisation would occur when such interventions evolved from violent, to peaceful, to non-existent.

But there are many obstacles to such a state of affairs. Conventional commercial branding depends to a large extent on open access to widely consumed commercial media, a condition that by definition is usually lacking in undemocratic countries; and finding ways to achieve a substantial branding effect without the use of media is indeed an interesting challenge, which without the increasing reach of the internet might seem entirely beyond the realms of possibility.

Who you are, how you are seen, and what you do, are all questions which are intimately and perhaps inextricably linked, which is why no state can hope to achieve its aims in the modern world without a mature and sophisticated fusion of PD and nation branding.

It is, not coincidentally, the reason for the subtle 'rebranding' of this Journal, from merely Place Branding to Place Branding and Public Diplomacy, which will be effected from the next volume (Volume $3 / 1^{3}$ ) of the journal, and it is my hope that over the coming years we will be able to welcome to these pages many more chapters of this fascinating - and entirely essential - encounter.

\section{Notes}

1 Anholt, S. and Hildreth, J. (2003) 'Brand America', Cyan Books, London.

2 Cold War US official Paul Nitze (1907-2004) to Gordon Gray, the first director of the Psychological Strategy Board (PSB), established in 1951 by President Truman 'to produce unified planning for American psychological operations' originally cited in Osgood, K. (2006) 'Total Cold War: Eisenhower's Secret Propaganda Battle at Home and Abroad' (Lawrence, Kansas: University of Kansas Press), p. 43, p. 45; appeared in Public Diplomacy Press and Blog Review for October 19-20, 2006.

3 Volume 3, Issue 1 Place Branding and Public Diplomacy, forthcoming.

\section{Simon Anholt Managing Editor}

